\title{
Metas para inflação e taxa de juros no Brasil: uma análise do efeito dos preços livres e administrados
}

\author{
HELDER FERREIRA DE MENDONÇA*
}

Inflation targets and exchange rate in Brazil: an analysis of the effect of market and administered prices. After surpassed more than half a decade since the adoption of inflation targeting in Brazil, it can be seen that maintaining a high interest rate is inherent to the strategy for the conduction of the monetary policy. The objective of this paper is to show that the present policy for defining the basic interest rate of the economy, based on the response to inflation considering both market and administered prices, is onerous for the Brazilian society. Based on findings from empirical evidence in the period 1999-2004, the adoption of a core inflation, a change in the time horizon for definition of targets, and, in common agreement between Banco Central do Brasil and National Treasury, a definition of these inflation targets, as a framework to increase efficiency of the monetary regime, creates possibilities for proposing a reduction on the Selic rate.

Key-words: interest rate; market prices; administrative prices; inflation; exchange.

JEL Classification: E52; E58.

\section{INTRODUÇÃO}

A adoção de âncoras nominais com o objetivo de reduzir e estabilizar a taxa de inflação é uma característica das economias latino-americanas. No final dos anos 1990, mesmo depois das crises asiática (1997) e russa (1998), variações de regime de câmbio fixo (dolarização, crawling peg, crawling band, currency board,

\footnotetext{
* Agradeço ao esforço de pesquisa realizado por Thiago Ramalho Vasco da Silva Lima e Tonyedson Pereira e Lana, e aos profícuos comentários realizados por dois pareceristas anônimos desta revista; contudo, as possíveis omissões ou imprecisões são de minha inteira responsabilidade. Professor do Departamento de Economia da UFF e Pesquisador do CNPq. E-mail: helderfm@hotmail.com. Submetido: fevereiro 2005; aceito: setembro 2005.
} 
etc.) representavam o principal mecanismo adotado por um grande número de países na América Latina. No ano de 1999, 11 países na região faziam uso de uma variação do regime de câmbio fixo. São exemplos: Panamá, Argentina, El Salvador, Bolívia, Costa Rica, Nicarágua, Colômbia, Chile, Venezuela, Honduras e Uruguai. Entretanto, a dificuldade em manter um regime monetário dependente de reservas em um cenário internacional instável fez com que ocorresse, nos últimos anos, um aumento expressivo no grupo de países que passaram a adotar o regime de câmbio flexível.

Sob um regime de câmbio flutuante, a política monetária deixa de ser endógena ao câmbio e torna-se necessário definir uma estratégia clara para a condução da política monetária em busca da estabilidade de preços. Com essa finalidade, a estratégia de metas para a inflação tem se mostrado uma alternativa factível para diversas economias. Atualmente, cinco países da região (Brasil, Chile, Colômbia, México e Peru) fazem uso do regime de metas para inflação. Entretanto, de forma diferente do caso de diversas economias desenvolvidas em que é utilizado um núcleo de inflação (exclusão dos efeitos provenientes de choques de oferta sobre o índice de preços) para a definição da meta, ${ }^{1}$ os países da América Latina consideram o índice de preços do consumidor sem qualquer expurgo.

O Brasil ilustra bem o caso acima. A política monetária é implementada levando em conta a inflação medida pelo Índice Nacional de Preços ao Consumidor Amplo (IPCA) cheio. Como forma de flexibilizar a estratégia monetária adotada, foram definidos intervalos de tolerância para a inflação. No caso de haver um descumprimento da meta definida pelo Conselho Monetário Nacional, o Decreto n. 3088, de 21 de junho de 1999, estabeleceu que o Presidente do Banco Central do Brasil (BCB) deve divulgar publicamente as razões do descumprimento por meio de uma carta aberta ao Ministro de Estado da Fazenda. Essa carta deve conter três pontos essenciais: (i) descrição detalhada das causas do descumprimento; (ii) providências para assegurar o retorno da inflação aos limites estabelecidos; e (iii) o prazo pelo qual se espera que as providências produzam efeito.

A principal justificativa para a estrutura implementada é a necessidade de desenvolver credibilidade para a condução da política monetária, o que por sua vez está relacionado, de forma direta, com a história de lhaneza do BC. ${ }^{2}$ No caso de o BC obter sucesso ao longo dos anos no alcance das metas para inflação, isso implica conquista de reputação. Essa reputação é muito importante nesse sistema porque os agentes passam a acreditar que a autoridade monetária será capaz de controlar a inflação futura, o que, por conseguinte, revela ganho de credibilidade.

Depois de transcorridos mais de meia década desde a adoção do regime de me-

\footnotetext{
${ }^{1}$ Como exemplo de países que adotam esse procedimento pode-se citar Austrália, Canadá, Nova Zelândia e Finlândia.

${ }^{2}$ Para uma análise dos principais elementos responsáveis pelo desenvolvimento de credibilidade, ver Blinder (2000).
} 
tas para inflação no Brasil, os resultados obtidos mostram que há a necessidade de um aprimoramento na estratégia implementada. Conforme reconhecido pelo BCB, a aceleração inflacionária observada a partir do segundo semestre de 2002 se deve à combinação da perda de confiança na evolução da economia brasileira com o aumento da aversão ao risco nos mercados internacionais. Ainda que exista o argumento predominante de que a política monetária não tem a capacidade de afetar a taxa de crescimento da economia no longo prazo, no curto prazo o custo da estratégia adotada não pode ser negligenciado. No biênio 2003-2004, a taxa de crescimento do Produto Interno Bruto no Brasil (0,6 e 5,2 respectivamente) situou-se abaixo da média de crescimento da América Latina (1,9 e 5,5 respectivamente). Ademais, no triênio 2003-2004-2005 a taxa de desemprego situou-se acima da média da região. Por último, deve-se ressaltar que o histórico do regime monetário adotado revela que as metas (considerando a banda para flutuação) somente foram obtidas em metade das oportunidades (vide Tabela 1).

Tabela 1: Metas para inflação no Brasil

\begin{tabular}{lccc}
\hline Ano & Meta & Banda & Inflação observada \\
\hline 1999 & $8 \%$ & $\pm 2 \%$ & $8,9 \%$ \\
\hline 2000 & $6 \%$ & $\pm 2 \%$ & $6,0 \%$ \\
\hline 2001 & $4 \%$ & $\pm 2 \%$ & $7,7 \%$ \\
\hline 2002 & $3,5 \%$ & $\pm 2 \%$ & $12,5 \%$ \\
\hline 2003 & $4 \%$ & $\pm 2,5 \%$ & $9,3 \%$ \\
\hline 2004 & $5,5 \%$ & $\pm 2,5 \%$ & $7,2 \%$ \\
\hline
\end{tabular}

Fonte: Banco Central do Brasil

O principal problema com o regime de metas para a inflação no Brasil reside no fato de que a dificuldade para a obtenção das metas faz com que a âncora nominal falhe no papel de convergência das expectativas do público para a meta anunciada. Dado que a taxa de juros é o principal instrumento da autoridade monetária para guiar as expectativas do público em um regime de metas para inflação, os sucessivos descumprimentos da meta anunciada levam a uma rigidez para baixo na definição da taxa Selic.

A rigidez para quedas na taxa de juros, além de levar ao conhecido resultado keynesiano de um efeito perverso sobre o produto devido à queda no nível de investimento, provoca um impacto considerável sobre a dívida pública. ${ }^{3} \mathrm{~A}$ razão para essa ponderação se justifica pelo fato de que o principal indexador da dívida pública brasileira é a taxa Selic. Logo, há um reforço para a rigidez na queda da taxa de juros devido a duas razões básicas: (i) aumento do risco de insolvên-

\footnotetext{
${ }^{3}$ A justificativa para a queda no nível de investimento se deve ao fato de que o retorno real proveniente dos juros tornar-se superior à eficiência marginal do capital em parte da economia.
} 
cia do governo: os investidores preferem transferir-se para outros mercados, provocando uma desvalorização cambial, o que, por conseguinte, pressiona para uma alta da inflação; e (ii) necessidade de aumento da carga tributária: o governo aumenta a alíquota dos impostos ou cria novas contribuições para evitar que a dívida pública entre em uma rota explosiva. O resultado desse procedimento é um encarecimento no custo de produção das empresas que tende a ser repassado para os seus preços.

Em suma, a rigidez para reduções na taxa Selic representa um entrave para incrementar o nível de investimento e, por sua vez, a taxa de crescimento da economia, e ainda, uma pressão para o aumento do endividamento público. Em relação ao último ponto, deve-se ressaltar que a tentativa de construir credibilidade mantendo uma taxa de juros elevada, obriga a necessidade da geração de superávits primários para conter a trajetória ascendente da razão dívida/PIB. Todavia, esse artifício não deve ser entendido como uma solução eficiente, pois representa recursos indisponíveis para a sociedade e prejudica a implementação de uma agenda microeconômica capaz de eliminar os gargalos no setor produtivo da economia.

Este artigo tem como objetivo mostrar que a atual política de definir a taxa de juros básica da economia, em reposta à inflação oriunda tanto dos preços livres quanto dos preços administrados, mostra-se onerosa para a sociedade brasileira. Ademais, é proposta a adoção de um núcleo de inflação e uma alteração no horizonte de tempo para a definição das metas, como forma de aumentar a eficiência do regime monetário e criar possibilidades para reduções na taxa Selic. Além desta introdução, o artigo apresenta-se dividido em mais quatro seções. A segunda seção apresenta os principais pontos presentes na literatura sobre a utilização dos índices de preços no regime de metas para inflação. A terceira seção mostra as principais características do IPCA e dos preços administrados no Brasil. A quarta seção visa analisar quais são os efeitos sobre a taxa Selic oriundos dos preços administrados por contrato ou monitorados, dos preços livres e da taxa de câmbio. Por último, é apresentada a conclusão do artigo.

\section{ÍNDICE DE PREÇOS E METAS PARA INFLAÇÃO}

Um dos pontos mais críticos do regime de metas inflacionárias é a definição de qual deve ser o índice de preços utilizado para medir a inflação. A maioria dos países adotou como meta de inflação o índice de preços ao consumidor (IPC). ${ }^{4}$ Entretanto, alguns autores, como Papadimitriou e Wray (1996), questionam a adequação do IPC. Os autores mencionados analisaram os efeitos da política monetária sobre o IPC nos EUA e verificaram que as medidas adotadas pelo Fed não

\footnotetext{
${ }^{4}$ Há diversos exemplos de países que utilizam o índice de preços do consumidor (sem qualquer expurgo) como medida da inflação: Brasil, Chile, Colômbia, Islândia, Israel, México, Noruega, Peru, Tailândia etc.
} 
se mostraram muito correlacionadas com a inflação. O principal argumento é que o IPC não representa uma medida confiável da inflação devido a dois aspectos: (i) ele não reflete de forma precisa o aumento de preços que ocorre no mercado; e (ii) ele não é perfeitamente controlado pela política monetária. O comportamento do IPC depende, sobretudo, de variações nos preços de três itens energia, aluguéis e saúde. Logo, o IPC não possui características fundamentais que o coloquem na condição de ser uma medida ideal da inflação.

Qualquer medida de inflação que seja usada para a formulação de política monetária deve refletir substancialmente as forças do mercado. Assim, o importante é entender os mecanismos pelos quais a política afeta a taxa de inflação. A razão para esse procedimento é que um dos principais problemas na condução da política monetária consiste em identificar se a maior parte da cesta que compõe o índice de preços é composta por itens cujos preços são capazes de serem controlados por uma ação de política. Considerando-se o aspecto normativo, é necessário que o índice de preços seja preciso e de fácil compreensão para o público. Além dessas qualidades, é desejável que o índice balizador para o nível de preços da economia não permita que choques aleatórios afetem a tendência da inflação. Portanto, é esperado que a adoção de um índice que utilize apenas o núcleo da inflação represente um melhor guia para a condução da política monetária.

Apesar da observação acima, deve-se ressaltar que há dissensões significativas sobre qual seria a melhor estrutura para definir a medida do núcleo de inflação. Em geral, a idéia de núcleo de inflação está associada com o conceito de tendência inflacionária. Para Bryan e Cecchetti (1993), o núcleo de inflação estaria relacionado com a taxa de crescimento da moeda. Não obstante, Quah e Vahey (1995) definem o núcleo de inflação como o componente da inflação mensurada que não causa impacto a médio e longo prazo no produto real. Em suma, a ampla possibilidade para a definição do núcleo de inflação é confusa e pode gerar um número considerável de medidas difíceis de serem interpretadas, principalmente quando elas seguem diferentes tendências.

Embora exista a dificuldade supracitada, o uso do núcleo de inflação é prática comum em diversos países. São exemplos: Austrália, Bélgica, Canadá, Cingapura, Espanha, EUA, Filipinas, Finlândia, França, Grécia, Holanda, Israel, Japão, Nova Zelândia, Portugal e Suécia. Na grande maioria desses países, os efeitos provenientes de alimentos, energia e impostos indiretos são retirados do índice de preços. Para evitar a exclusão espúria de componentes, tem sido empregado o método de estimadores de influência limitada, cujos principais indicadores são a mediana ponderada e a média aparada. No Brasil, a Fundação Getúlio Vargas tem divulgado o núcleo de inflação para o IPC com base na técnica de médias aparadas, enquanto que o Instituto de Pesquisa Econômica Aplicada divulga resultados do núcleo de inflação para o IPCA fazendo uso da técnica de suavização de médias aparadas (tendência comum dos diversos componentes do índice e tendência comum dos vários índices de inflação). ${ }^{5}$

\footnotetext{
${ }^{5}$ Para uma avaliação de medidas de núcleo de inflação para o Brasil, ver Figueiredo (2001).
} 
No contexto de um núcleo de inflação, a tarefa principal para os formuladores de política econômica consiste em extrair o máximo de informações possíveis, depurando a volatilidade ou o ruído dos dados. Dessa forma, é possível fazer melhores julgamentos sobre as perspectivas para a inflação que possam revelar informações sobre os choques que afetam a economia.

Mankikar e Paisley (2002) apontam duas razões básicas para que a inflação tenha ruídos. Segundo os autores sobreditos, em um mundo com total flexibilidade de preços e com ausência de política monetária, um choque em determinado setor implicaria mudanças instantâneas nos preços relativos, deixando inalterados o índice agregado de preços e a taxa de inflação agregada. Entretanto, o cenário apresentado é pouco provável na prática. O fato dos preços não serem totalmente flexíveis no curto prazo e dos preços relativos levarem um certo tempo para se ajustar, faz com que a política monetária torne-se um importante instrumento para acomodar essa situação transitória. O ponto crucial é que os responsáveis pela condução da política monetária devem ser capazes de distinguir entre as mudanças nos preços relativos e aquelas oriundas de pressões inflacionárias subjacentes. Nesse sentido, embora seja muito difícil distinguir, de forma imediata, quais são as mudanças de preços que de fato contêm informações sobre a inflação e aquelas que refletem apenas mudanças temporárias ou sazonais no nível de preços, o núcleo de inflação pode ser potencialmente útil para atenuar essa dificuldade.

\section{A IMPORTÂNCIA DOS PREÇOS} ADMINISTRADOS NA COMPOSIÇÃO DO IPCA

O índice de preços oficial definido pelo Conselho Monetário Nacional para o regime de metas para a inflação é o IPCA disponibilizado pelo IBGE. O IPCA mede a variação de preços nos bens consumidos por famílias com renda de 1 a 40 salários mínimos, em nove regiões metropolitanas (Belém, Belo Horizonte, Curitiba, Fortaleza, Porto Alegre, Recife, Rio de Janeiro, Salvador e São Paulo), no Distrito Federal e no município de Goiânia. O IPCA é um índice de Laspeyres que calcula a variação dos preços de bens e serviços entre dois períodos (comparação dos preços vigentes nos trinta dias do período de referência e com os trinta dias do período base), ponderando a participação dos gastos com cada bem no consumo total. A estrutura atual do IPCA encontra-se dividida em nove grupos: Alimentação e Bebidas; Habitação; Artigos de Residência; Vestuário; Transportes; Saúde e Cuidados Pessoais; Despesas Pessoais; Educação; e Comunicação.

Um ponto de grande importância para a análise do regime de metas para inflação advém do fato de o IPCA ser muito sensível aos reajustes nos preços administrados por contratos e monitorados (que dependem da autorização prévia do governo ou de algum órgão do poder público). Devido à alteração da estrutura do IPCA, em agosto de 1999, os preços administrados passaram a ter um peso que corresponde a $28,7 \%$ na sua composição. 
Deve-se ressaltar que cada variável que compõe os preços administrados tem diferentes políticas de reajustes, o que, por conseguinte, influencia outros preços livres ou administrados. Um atributo dos itens que compõem os preços administrados é que eles possuem baixa sensibilidade à oferta e à demanda, como, por exemplo, tarifas de energia e telefone fixo. Ademais, há a presença de um caráter inercial nos preços administrados, uma vez que os reajustes são feitos a partir de contratos atrelados à variação passada dos índices de preços.

Conforme pode ser observado por meio da Tabela 2, observa-se que os preços administrados que entram na composição do IPCA, dividem-se em impostos e taxas, serviços de utilidade pública e derivados de petróleo. Constata-se que a quantidade de itens cujos preços são determinados no âmbito federal, tem maior participação na composição do índice, o que por sua vez denota uma maior possibilidade de pressão inflacionária resultante da elevação dos preços nos itens relacionados. Em especial, os setores de energia elétrica, de derivados de petróleo e de telecomunicações sofreram importantes mudanças nos últimos anos.

Tabela 2: Preços determinados por contrato na composição do IPCA

\begin{tabular}{ll}
\hline Âmbito municipal ou estadual & \multicolumn{1}{c}{ Âmbito federal } \\
\hline - Gás encanado & - Derivados de petróleo (gasolina, óleo diesel, \\
- Imposto predial e territorial & óleo para veículos, gás de botijão) \\
urbano - IPTU & - Álcool combustível \\
- Taxa de emplacamento & -Tarifa de energia elétrica de consumo residencial \\
e licenciamento de veículos & - Tarifas de telefonia e correios (telefone fixo, \\
- Taxa de água e esgoto & telefone público, telefone celular, correio) \\
- Transporte público (Ônibus urbano, & • Pedágio \\
ônibus intermunicipal, ferry-boat, & -Transporte público (passagens de avião, \\
metrô e táxi) & ônibus interestadual, trem, navio e barco) \\
& - Jogos lotéricos \\
& - Cartório \\
\hline
\end{tabular}

Fonte: IBGE

A partir de 1995, o setor de energia elétrica foi dividido nas atividades de geração, transmissão e distribuição, e os contratos assinados entre as empresas concessionárias e a Agência Nacional de Energia Elétrica (Aneel) passaram a determinar os reajustes no setor. Os contratos estabeleceram um reajuste anual das tarifas em duas partes. A primeira inclui os custos exógenos à empresa (compra de energia, impostos diretos, encargos e a conta de consumo de combustíveis) sendo reajustados pela variação dos gastos desses itens. A segunda parte está relacionada aos custos internos da empresa que são reajustados pelo Índice Geral de Preços ao Mercado (IGP-M). Ademais, os contratos permitem que as concessionárias solicitem revisões de suas tarifas com o objetivo de manter o equilíbrio econômico. 
Os derivados de petróleo, a partir de 2002, sofreram medidas para a desregulamentação do setor de combustíveis. O processo de desregulamentação incluiu a substituição da Parcela de Preço Específica (PPE) pela Contribuição por Intervenção no Domínio Econômico (Cide) e a liberalização de preços, fretes e margens de lucro em todo o país. Os controles de preços que existiam sobre produtos como gasolina, óleo diesel e botijões de gás (GLP) nas refinarias de petróleo foram eliminados e os subsídios foram retirados. Uma peculiaridade desse setor é que os preços dos derivados do petróleo são influenciados de uma forma direta pelo preço internacional do petróleo e da variação cambial. Assim, as variações no preço do petróleo provocam alterações indiretas sobre os preços administrados.

No setor de telecomunicações, em decorrência do processo de privatizações implementado, ocorreu um processo de reestruturação que levou à redução dos subsídios, e as tarifas passaram a ser reajustadas, levando em consideração o custo da prestação de serviços. O reajuste das tarifas é determinado pelo contrato estabelecido entre as empresas concessionárias e a Agência Nacional de Telecomunicação (Anatel), sendo que a fórmula de reajuste inclui um fator que tem por finalidade dar transparência aos ganhos de produtividade aos usuários do serviço.

Devido à desvalorização do Real no início de 1999 e à sensibilidade dos preços administrados ao câmbio, uma vez que alguns deles encontram-se indexados aos índices gerais de preços, foi observada uma trajetória acima daquela verificada para os preços livres (vide Figura 1). Um outro fator preponderante que pressionou os preços administrados para cima foi o crescimento do preço internacional do petróleo, que provocou uma elevação nos preços dos seus derivados e nos produtos que os utilizam como matéria-prima. Além dos fatores supracitados, o processo de privatização de serviços públicos e a retirada de subsídios também contribuíram para a trajetória observada nos preços administrados.

É notório o argumento de que o BCB utiliza a taxa Selic como principal instrumento para o controle da inflação. Entretanto, uma parte não-desprezível da inflação medida pelo IPCA não é sensível à taxa Selic, uma vez que os preços administrados são, em sua maioria, determinados por contratos e dependem da observação da inflação passada medida por IGPs. Logo, a taxa de juros não estaria sendo utilizada de forma adequada. A sua aplicação correta deveria levar em conta pressões de demanda que levam a elevações nos preços livres. A resposta da taxa de juros à inflação dos preços livres e à inflação dos preços administrados é analisada sob uma perspectiva econométrica na seção a seguir. 


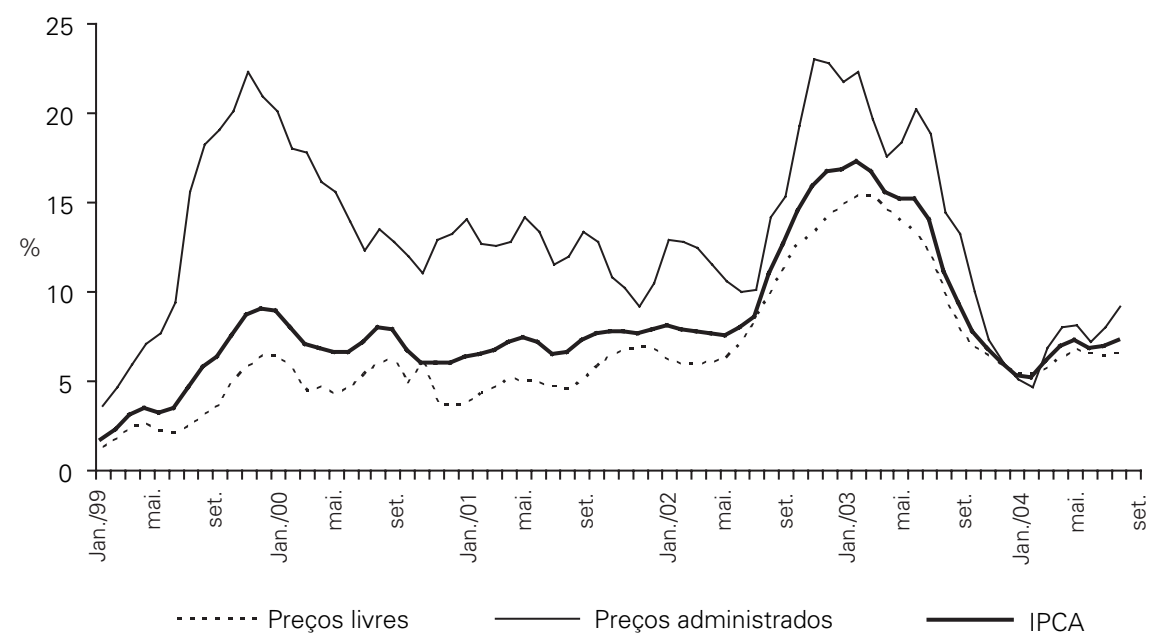

Nota: Variações percentuais acumuladas em 12 meses. Fonte de dados: Banco Central do Brasil.

\section{RESULTADOS EMPÍRICOS}

Com o objetivo de verificar a determinação da taxa de juros pelo BCB em resposta à inflação oriunda dos preços livres (liv) e administrados $(\mathrm{adm})$ no período posterior à introdução do regime de metas para inflação, é feita uma estimação (Mínimos Quadrados Ordinários) baseada em uma regra de reação para o BCB, do tipo Taylor. Assim, a equação estimada é dada por:

(1) $i_{t}=\alpha_{1}+\alpha_{2} i_{t-1}\left(1-\alpha_{2}\right)\left[\alpha_{3}\left(l v_{t-1}-\pi *_{t-1}\right)+\alpha_{4}\left(a d m_{t-1}-\pi *_{t-1}\right)\right]$

onde $i=$ taxa de juros nominal (Selic); liv = inflação dos preços livres acumulada nos últimos doze meses; $\pi^{*}=$ meta de inflação para os últimos doze meses; e $a d m=$ inflação dos preços administrados acumulados nos últimos doze meses.

Uma primeira condição a ser verificada antes de estimar o efeito dos preços livres e administrados sobre a taxa Selic é verificar se as séries possuem raiz unitária. No caso das séries não serem estacionárias, há grande probabilidade dos resultados obtidos serem espúrios. Logo, com o objetivo de testar a existência ou não de raiz unitária das séries selic, liv e $a d m$ foram realizados os testes DickeyFuller ampliado (ADF) e Phillip-Perron (PP). Ambos os testes indicam a aceitação da hipótese nula (séries não estacionárias) para os valores originais das séries ao nível de significância de $99 \%$. Por outro lado, em relação às primeiras diferenças, a hipótese nula é rejeitada para todas as séries ao nível de significância de 1\% (vide Tabela A.1 - Apêndice). Portanto, as séries são integradas de primeira ordem, isto é, I(1). 
O resultado acima sugere que seria adequado regredir as variáveis em suas primeiras diferenças; entretanto, esse procedimento pode levar a uma perda da relação de longo prazo entre elas. Assim, é necessário verificar se uma combinação linear entre as séries é estacionária, mesmo sabendo-se que as séries são individualmente não-estacionárias. Em outras palavras, é preciso constatar se as séries são co-integradas, o que implicaria que a regressão proposta, com as variáveis em nível, apresentaria estatísticas confiáveis.

Os resultados do teste de co-integração proposto por Johansen (1991) teste de razão de verossimilhança (teste LR) com base na significância dos autovalores estimados - indica que a estatística do traço rejeita a hipótese de não co-integração (ao nível de significância de $5 \%$ ), mas não a hipótese de que há mais de uma relação de co-integração (vide Tabela A.2 - Apêndice) ${ }^{6}$ Como as séries são co-integradas e, portanto, há uma relação de equilíbrio de longo prazo entre as séries, a equação 1 pode ser estimada com as variáveis em nível tal que os resultados não se mostram espúrios.

A estimativa para a taxa de juros, levando em consideração as observações mensais disponibilizadas pelo BCB no período que se estende de julho de 1999 a novembro de 2004, é dada por:?

$$
\begin{aligned}
& \text { (2) } i_{t}=\underset{(3,131)^{*}}{2,021} \underset{(20,748)^{*}}{0,859} i_{t-1}+(1-0,859)\left[\underset{(2,534)^{* * *}}{0,815}\left(l i v_{t-1}-\pi{ }_{t-1}^{*}\right)+\underset{(3.588)^{*}}{0,383\left(a d m_{t-1}-\pi{ }_{t-1}\right)}\right] \\
& \mathrm{R}^{2}=0,945, \mathrm{n}=65.8
\end{aligned}
$$

Os resultados obtidos mostram um comportamento para a taxa de juros estimada muito próxima à da taxa Selic observada no período (vide Figura 2). O alto valor e significância da constante revelam que a função de reação da autoridade monetária apresenta um componente robusto para a elevação da taxa de juros. A importância da taxa de juros defasada também é atestada, uma vez que apresenta valor e significância estatística elevados. Em relação à resposta da taxa de juros aos preços livres e administrados, observa-se, como esperado, uma maior sensibilidade aos preços livres do que aos administrados. Não obstante, a resposta dos juros aos preços administrados, além de não ser desprezível, apresenta sig-

\footnotetext{
${ }^{6} \lambda$ traço - a hipótese nula corresponde ao número de vetores co-integrantes ser igual a $\mathrm{r}$, contra a hipótese alternativa de que o número de vetores co-integrantes é maior que r. A especificação selecionada para o teste considera constante na equação de co-integração.

${ }^{7}$ Uma primeira estimativa para a equação 1 encontra-se em Figueiredo e Ferreira (2002). Entretanto, é importante ressaltar que a análise feita pelos autores mencionados compreende o período entre abril de 1999 e setembro de 2002. A justificativa para uma nova estimação é que os resultados obtidos pelos autores mencionados não podem ser entendidos como robustos, pois foram realizados para um período muito curto (apenas 42 observações e sem estarem totalmente situadas no período relativo às metas inflacionárias).

$8 *(* *)$ Significativo ao nível de $1 \%(5 \%)$. Estatísticas-t, entre parênteses, consideram o teste de heterocedasticidade de White (1980).
} 
nificância estatística bastante elevada. Logo, os preços administrados têm contribuído para dificultar possíveis reduções na taxa Selic.

Figura 2: Evolução da Selic e da taxa de juros estimada

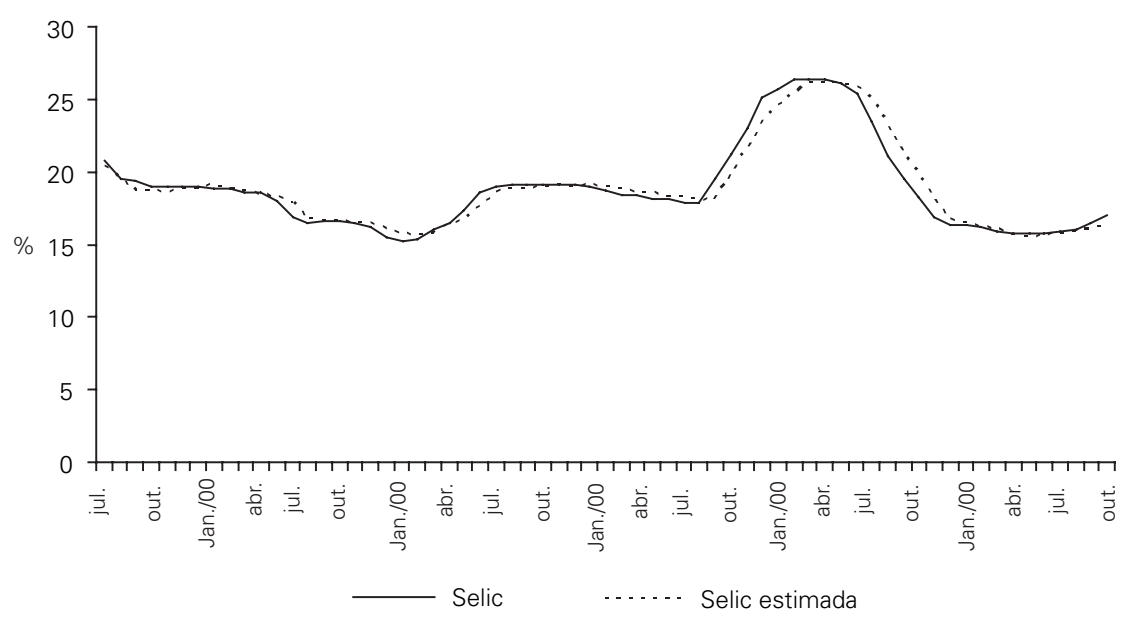

Com o objetivo de verificar o impacto dos preços administrados e livres sobre a taxa Selic (modelo 1) e o quão onerosa para a sociedade é a atual política que segue um regime de metas de inflação baseado no IPCA (modelo 2), a análise, a seguir, toma como referência um modelo auto-regressivo vetorial (VAR). A vantagem do modelo em consideração é que, ao contrário dos sistemas de equações simultâneas, os modelos VAR têm sido considerados mais apropriados para a análise de relações interligadas e de impactos dinâmicos provocados por choques. $^{9}$

Além das variáveis utilizadas para a estimação da equação 2 e utilizando o mesmo período de dados, no modelo 1, é introduzida na análise a taxa de câmbio (câmb. - R \$/US\$ - comercial — venda - média R - mensal). A presença da taxa de câmbio no modelo é importante porque por meio dela é possível verificar, por exemplo, qual a sensibilidade da taxa Selic frente a flutuações cambiais. Em relação ao modelo 2, dado o objetivo de analisar o ônus da política monetária para a sociedade, além da taxa Selic também foram consideradas as seguintes variáveis:

(i) inflação (INF) - medida pelo IPCA - variações percentuais em 12 meses - divulgada pelo IBGE;

(ii) produção física industrial (PFI) - série extraída da Pesquisa Industrial Mensal - Produção Física feita pelo IBGE; e

(iii) taxa de desemprego (DESEMP) - obtida a partir da Pesquisa de Em-

\footnotetext{
${ }^{9}$ No período recente, diversos trabalhos aplicando VAR para a economia brasileira têm sido realizados. Dentre os diversos pode-se citar Gonçalves (2001), Minella (2003), e de Mendonça (2004, 2003).
} 
prego e Desemprego (Seade e Dieese/PED) para a região metropolitana de São Paulo. ${ }^{10}$

Da mesma forma que as séries envolvidas na estimativa da equação 1 , as séries supracitadas também são I(1) (vide Tabela A.1 - Apêndice). Portanto, as séries empregadas nos VARs devem ser utilizadas na primeira diferença. Em relação à definição do modelo aplicado para a elaboração dos VARs, foram utilizados os critérios de Akaike (AIC), Schwarz (SIC) e Hannan-Quinn (HQ). ${ }^{11}$ Os resultados obtidos denotam que ambos os modelos devem empregar duas defasagens e o uso de constante (vide tabela A.3 - Apêndice).

Devido à reconhecida dificuldade na interpretação dos coeficientes estimados para um VAR, a utilização da decomposição da variância e a função impulso-resposta parcial são normalmente utilizadas na análise. Em razão dos dados utilizados na amostra serem mensais, é levado em consideração o efeito de um choque no transcorrer de 12 meses.

\section{Análise do Modelo 1}

De acordo com a Tabela 3, em que é apresentada a decomposição da variância da taxa Selic, observa-se que a importância da própria taxa Selic na explicação de sua variância é significativa (cerca de 30\% depois de 1 ano). Ademais, a função impulso-resposta mostra que são necessários quase 12 meses para que o efeito de alta provocado por um choque seja dissipado (vide Figura 3 - canto inferior direito). Essa constatação indica que uma elevação na taxa Selic tende a não ser eliminada de forma rápida.

Em relação ao câmbio, observa-se que a importância relativa dessa variável na variância da taxa Selic é bastante significativa (vide Tabela 3). Além disso, o gráfico referente à resposta da Selic ao impulso provocado por um choque sobre o câmbio, mostra que o efeito de alta na taxa de juros não é eliminado ao longo de 12 meses (vide Figura 3 - canto superior esquerdo). O resultado encontrado sugere que a autoridade monetária usa de forma efetiva a taxa de juros para neutralizar pressões inflacionárias oriundas de choques sobre a taxa de câmbio. Um bom exemplo desse procedimento é observado no ano de 2001 quando ocorreu acentuada elevação na taxa Selic para conter os efeitos da desvalorização cambial, provenientes da crise argentina e dos ataques terroristas aos EUA, sobre a inflação.

\footnotetext{
${ }^{10}$ Compreende desemprego oculto (trabalho precário e desemprego por desalento) e desemprego aberto.

${ }^{11} \mathrm{AIC}=-2(1 / \mathrm{T})+2(\mathrm{k} / \mathrm{T}), \mathrm{SC}=-2(1 / \mathrm{T})+\mathrm{k} \log (\mathrm{T}) / \mathrm{T}$ e $\mathrm{HQ}=-2(1 / \mathrm{T})+2 \mathrm{k} \log (\log (\mathrm{T})) / \mathrm{T}$; considera uma regressão com k parâmetros estimados usando T observações, 1 é o valor do log da função probabilidade com $\mathrm{k}$ parâmetros estimados.
} 
Tabela 3: Decomposição da variância - Selic (Modelo 1)

\begin{tabular}{ccccc}
\hline Mês & Câmbio & Liv & Adm & Selic \\
\hline 1 & 3,696286 & 2,384679 & 0,100099 & 93,81894 \\
\hline 2 & 6,359987 & 9,272348 & 0,814582 & 83,55308 \\
\hline 3 & 11,34214 & 11,58210 & 4,186822 & 72,88894 \\
\hline 4 & 18,69217 & 10,59236 & 8,031844 & 62,68363 \\
\hline 5 & 26,91856 & 8,457426 & 10,44617 & 54,17785 \\
\hline 6 & 34,64829 & 6,492295 & 11,23222 & 47,62720 \\
\hline 7 & 41,23625 & 5,141529 & 10,98448 & 42,63773 \\
\hline 8 & 46,55091 & 4,428426 & 10,28762 & 38,73304 \\
\hline 9 & 50,66272 & 4,242349 & 9,500894 & 35,59403 \\
\hline 10 & 53,67121 & 4,448018 & 8,802794 & 33,07798 \\
\hline 11 & 55,65567 & 4,913119 & 8,274108 & 31,15710 \\
\hline 12 & 56,69246 & 5,511679 & 7,951779 & 29,84408 \\
\hline
\end{tabular}

A variância da Selic em relação aos preços livres e administrados apresenta um comportamento bastante interessante. Até o quarto mês depois da ocorrência de um choque, a importância relativa dos preços livres para a explicação da variância da Selic é maior do que a atribuída aos preços administrados. Entretanto, depois do quinto mês, a importância dos preços administrados na explicação da variância da taxa Selic torna-se proeminente. Esse resultado implica que a taxa Selic é mais sensível aos preços livres do que aos administrados no curto prazo (pico no terceiro mês). Não obstante, o maior efeito dos preços administrados sobre a taxa de juros é observado no sexto mês, o que, por conseguinte, denota uma rigidez para reduções na Selic. A justificativa para a rigidez se deve ao fato de que quando começa a declinar o efeito oriundo dos preços livres, o impacto proveniente dos preços administrados torna-se mais acentuado. A análise da função impulso-resposta para os dois casos ratifica a idéia acima (vide Figura 3). É observado que o efeito de uma alta nos preços livres tende a provocar uma elevação na taxa Selic que é eliminada no sétimo mês, ao passo que o efeito proveniente de um aumento nos preços administrados perdura por cerca de 11 meses. 
Figura 3: Funções de resposta a impulso para o VAR (Modelo 1)

Resposta a impulso de 2 D.P.
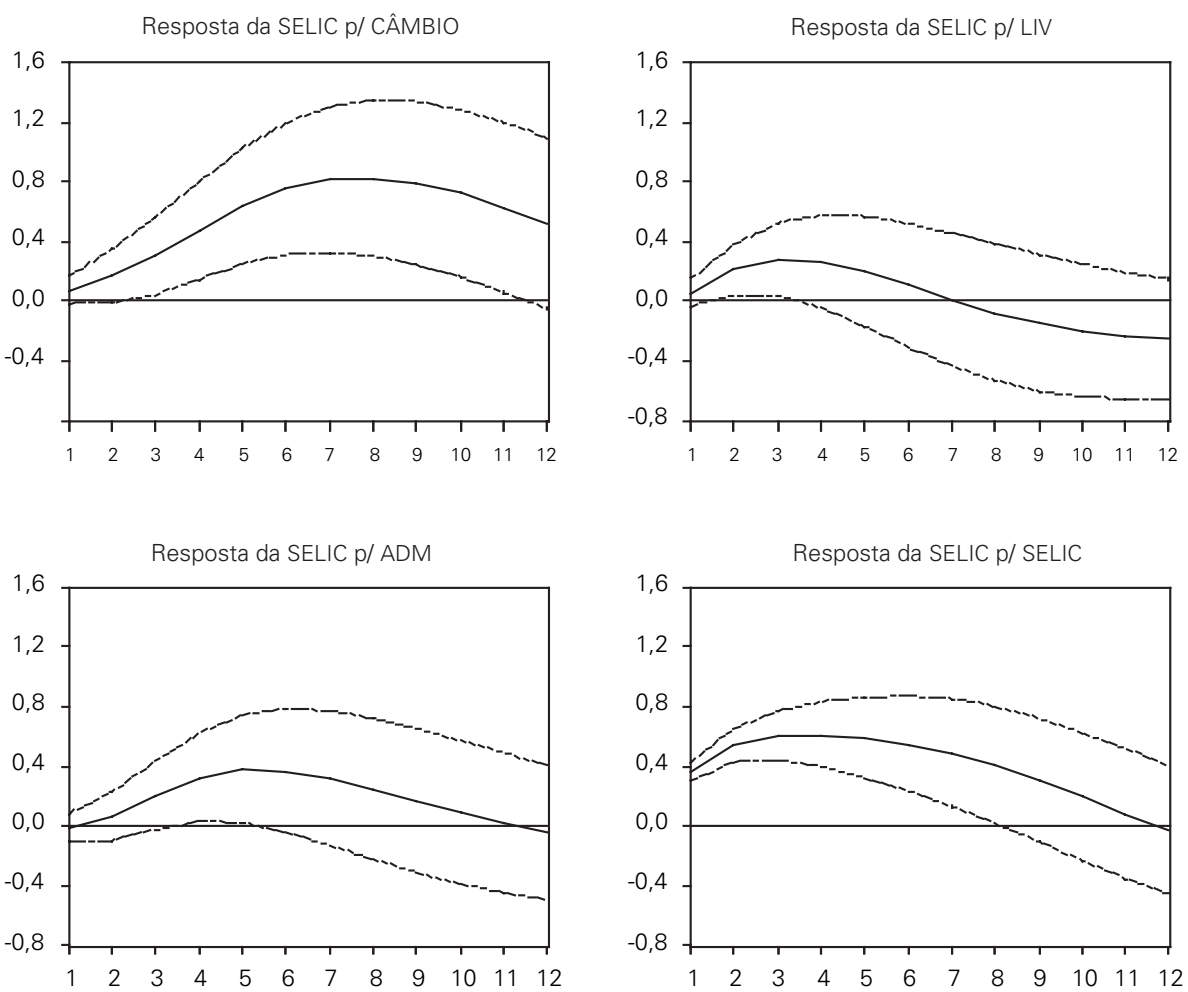

Nota: Ordem das séries — câmbio, liv, adm e Selic. ${ }^{12}$

\section{Análise do Modelo 2}

A análise impulso-resposta para a Selic (vide Figura 4 - canto superior esquerdo) revela que um choque positivo sobre a própria variável tende a provocar uma elevação que perdura por mais de 12 meses. Ademais, a análise da decomposição da variância revela que a taxa de juros é a grande responsável na explicação de sua variância ( $83 \%$ - vide tabela 4$)$. Esse resultado sugere que o uso de uma política monetária baseada em elevações na taxa de juros básica da economia para combater a inflação, tende a criar uma rigidez para reduções na taxa de juros.

${ }^{12}$ As séries foram ordenadas de diversas formas, mas os resultados não apresentaram mudança significativa. 
Tabela 4: Decomposição da variância — Selic, INF, PFI e DESEMP pela Selic (Modelo 2)

\begin{tabular}{lcccc}
\hline Mês & Selic & INF & PFI & DESEMP \\
\hline 1 & 100,0000 & 1,106610 & 0,420649 & 0,874194 \\
\hline 2 & 94,75861 & 6,077311 & 2,666008 & 1,236538 \\
\hline 4 & 88,92195 & 17,44966 & 5,092718 & 2,391083 \\
\hline 5 & 85,07932 & 32,93481 & 7,262519 & 4,646728 \\
\hline 6 & 83,38162 & 46,94138 & 9,182779 & 7,896914 \\
\hline 7 & 83,06181 & 56,70147 & 10,96883 & 11,59831 \\
\hline 8 & 83,32346 & 62,57777 & 12,62375 & 15,15829 \\
\hline 10 & 83,64373 & 65,79465 & 14,03947 & 18,36568 \\
\hline 11 & 83,77340 & 67,34617 & 15,08510 & 21,33475 \\
\hline 12 & 83,63876 & 67,83803 & 15,69074 & 24,15579 \\
\hline & 83,25489 & 67,61257 & 15,87936 & 26,73261 \\
\hline 82,67937 & 66,89413 & 15,75046 & 28,86325 \\
\hline
\end{tabular}

No que se refere ao efeito de um aumento da Selic na INF, o gráfico localizado no canto superior direito na Figura 4, denota que são necessários mais de doze meses para que a pressão inflacionária seja eliminada. Além disso, a importância relativa da Selic na explicação da variância da INF é muito significativa (67\% — vide Tabela 4). Esses resultados corroboram o que foi apresentado na subseção anterior. A lentidão para a queda da inflação deve-se ao fato de que parte dela, como, por exemplo, a inflação oriunda dos preços administrados, é insensível às ações da política monetária. Logo, é preciso que a taxa de juros se eleve acima do que seria necessário para eliminar uma pressão inflacionária sobre os preços livres. Em outras palavras, dado que o BCB não tem controle perfeito sobre a inflação, há a necessidade de uma maior taxa de juros e um maior tempo para que seja implementada com êxito uma política de desinflação. 
Figura 4: Funções de resposta a impulso para o VAR (Modelo 2)

Resposta a impulso de 2 D.P.
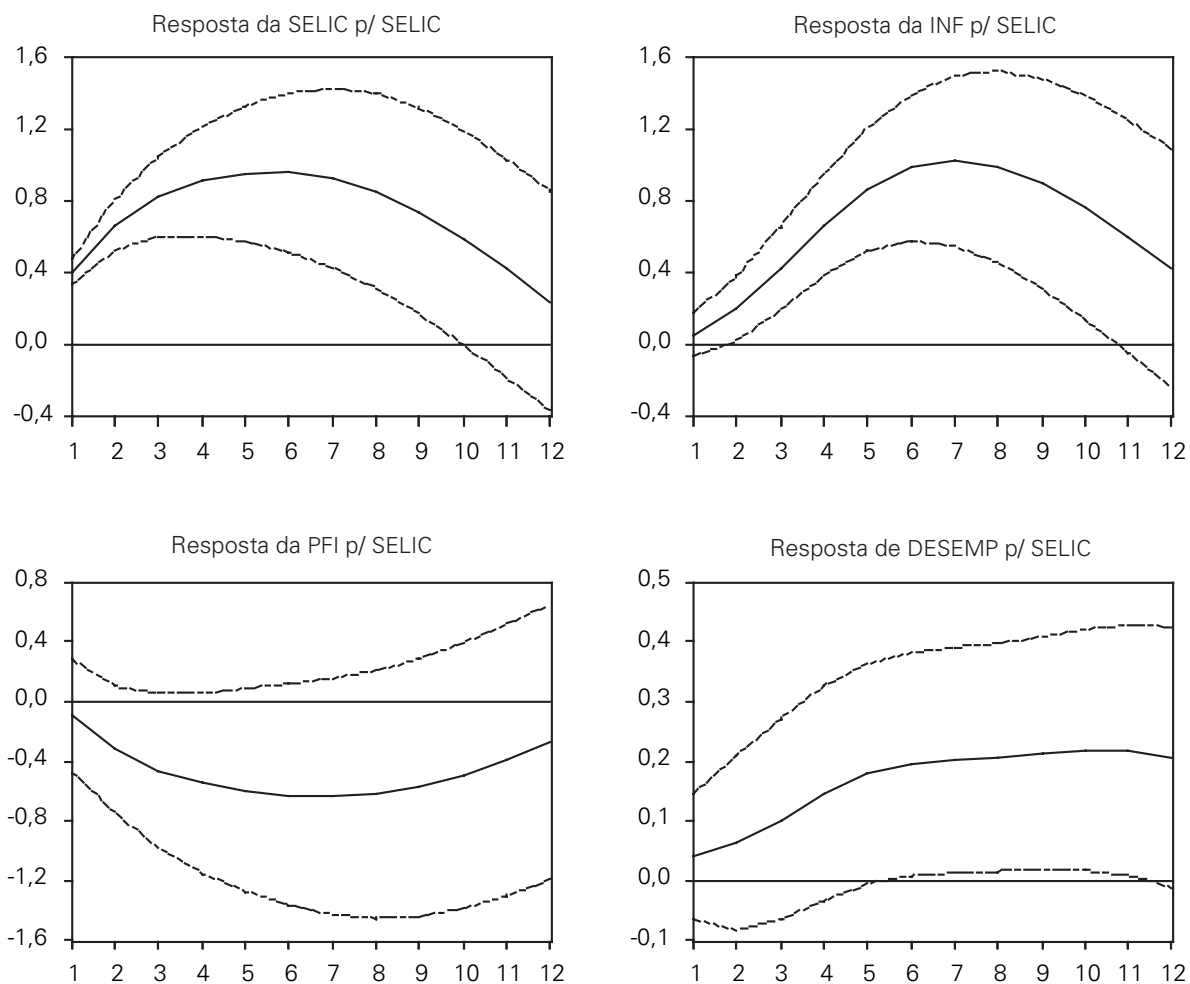

Nota: Ordem das séries - Selic, inf, pfi e desemp..$^{13}$

Quanto ao impacto de uma elevação da Selic sobre a PIF, a função impulsoresposta mostra, da mesma forma que nos casos anteriores, que o efeito negativo supera doze meses para ser eliminado (gráfico situado no canto inferior esquerdo da Figura 4). Outrossim, o efeito da Selic na explicação da variância da PIF não deve ser negligenciado (16\% — vide Tabela 4). Portanto, verifica-se que, mesmo no caso em que há sucesso no controle da inflação via elevação na taxa de juros, o custo dessa estratégia (queda na atividade econômica superior a 1 ano) não pode ser desprezado.

A função impulso-resposta do impacto da Selic sobre o DESEMP (vide gráfico localizado no canto inferior direito) revela que uma elevação na Selic provoca um aumento permanente na taxa de desemprego. Ademais, a análise da de-

${ }^{13}$ Tal como no modelo anterior, as séries foram ordenadas de diversas formas, mas os resultados não apresentaram mudança significativa. 
composição da variância indica que o efeito da Selic sobre o DESEMP $(29 \%$ vide Tabela 4) não pode ser ignorado. Essa é uma observação importante porque sugere que a utilização da taxa de juros como principal instrumento para neutralizar pressões inflacionárias, tal como no caso anterior, acarreta uma elevação no custo social (aumento da taxa de desemprego).

\section{CONSIDERAÇÕES FINAIS}

Devido ao fato de os preços administrados apresentarem variações superiores à taxa de inflação oficial no período de 1999 a 2004, houve uma pressão inflacionária que exigiu uma resposta da taxa de juros acima do que seria necessário para conter a inflação proveniente dos preços livres. Entretanto, é questionável, para uma economia que possui uma das taxas de juros mais elevadas do mundo, o argumento dos técnicos do BCB de que é preciso neutralizar, pela elevação na taxa Selic, os efeitos secundários dos choques causados pelos preços administrados. Os preços administrados possuem uma dinâmica com forte componente backward-looking (parte dos itens tem reajustes com base na variação passada dos IGPs) e apresentam grande sensibilidade aos preços internacionais do petróleo e às desvalorizações da taxa de câmbio. Destarte, os preços administrados são responsáveis por uma maior persistência da taxa de inflação, o que, por sua vez, exige maior custo social (taxas de juros elevadas) para que ocorra um processo de desinflação devido à baixa sensibilidade às condições de oferta e demanda.

O problema não está em ter a taxa de juros como principal instrumento de combate à inflação, mas no seu uso indiscriminado para neutralizar todos os tipos de inflação. No caso dos preços administrados, a causa da inflação não está relacionada a um excesso de demanda, mas à capacidade das empresas aumentarem seus preços mesmo quando a demanda está fraca (inflação administrativa ou de custos). Um outro fator que não deve ser negligenciado é que a proteção dada às empresas, por meio de contratos garantindo a manutenção da renda por meio da elevação de preços, implica a presença de um componente inercial na inflação. Logo, a taxa de juros não é o instrumento adequado para neutralizar uma pressão inflacionária oriunda dos preços administrados.

As evidências empíricas apresentadas revelam que não devem ser desprezados os efeitos negativos que uma política monetária contracionista implica para a economia (queda na atividade econômica, aumento na taxa de desemprego etc.). Ademais, também foi verificado que a taxa Selic, além de responder às variações nos preços livres e administrados, é bastante sensível a flutuações na taxa de câmbio. Essa observação representa um ponto favorável ao argumento apresentado por Bresser-Pereira e Nakano (2002) de que a existência de papéis múltiplos para a taxa de juros representa um entrave para a sua redução.

A adoção do IPCA cheio tem se mostrado inadequada para a conquista de credibilidade do regime de metas para inflação. $\mathrm{Na}$ totalidade das vezes em que a meta foi alcançada, a inflação situou-se no limite superior da banda. Essa é uma 
observação preocupante, pois há a necessidade do prosseguimento de uma política monetária contracionista para tentar trazer a inflação para o centro da meta. Além disso, o fato de as expectativas inflacionárias encontrarem-se acima do centro da meta implica que qualquer choque sobre a economia leva a novas elevações na taxa de juros para conter o temor de um possível descontrole inflacionário. Ou seja, há a necessidade de uma mudança na estratégia de condução da política monetária para que o custo da manutenção de uma elevada taxa de juros seja atenuado.

Uma boa alternativa para o problema, como indicado por Bresser-Pereira e Nakano (2002), seria a adoção de um núcleo de inflação (exclusão dos componentes transitórios da inflação), uma vez que seria capaz de atenuar os problemas advindos dos preços administrados e do câmbio. De forma adicional, a definição da meta de inflação, no início de cada ano em comum acordo entre o BCB e o Tesouro Nacional, representaria um incremento na qualidade para a definição da meta. Dessa forma, seria aumentada a transparência do esforço do governo em assegurar o controle da inflação sem colocar em risco a sustentabilidade da dívida pública.

Deve-se ressaltar que mesmo em uma situação hipotética de longo prazo que indique uma certa convergência entre os diferentes índices de inflação, a estratégia de adoção de um núcleo de inflação mostra-se relevante. É verdade que a pressão dos preços administrados, considerando-se a hipótese supracitada, pode desaparecer e até mesmo contribuir para uma queda na inflação. Não obstante, uma das vantagens da adoção do núcleo de inflação é evitar a necessidade de uma maior volatilidade na taxa de juros para neutralizar choques. Ademais, a situação mais freqüente na economia brasileira refere-se à possibilidade de overshooting cambial ao invés de undershooting. O ano de 2005 foi marcado por uma baixa taxa de câmbio devido à manutenção de uma política monetária excessivamente contracionista. Logo, é de se esperar que o impacto dos preços administrados sobre a inflação desse ano seja desprezível. Entretanto, o ano de 2006 foi marcado por uma nova eleição presidencial. Diante da atual crise política, não será surpresa a possibilidade de repetição de um novo processo de desvalorização cambial, tal como ocorreu na eleição presidencial anterior. Portanto, é importante que a política econômica esteja preparada para responder a problemas potenciais da economia brasileira e não repetir os erros cometidos no passado recente.

Alguns teóricos defendem o argumento de que a adoção do núcleo de inflação pode não ser bem entendida pelos agentes econômicos devido ao histórico de manipulação da inflação por parte do governo, e que, por conseguinte, a política monetária seria ainda mais restritiva para compensar a perda de reputação e/ou credibilidade. Entretanto, é importante lembrar que o contexto em que o governo manipulava os índices de preços era completamente díspar do momento atual. Por exemplo, a malsucedida experiência de dezembro de 1984, de que a correção monetária seria igual ou maior que o IGP-DI expurgado, encontrava-se sob um governo militar. Ou seja, em um contexto em que não há democracia, as 
arbitrariedades podem ocorrer com maior freqüência e a opacidade é a tônica na condução da política econômica. Conforme salientado por Arida (1999), a abertura democrática reduziu drasticamente a tolerância da sociedade diante do processo inflacionário. Um bom exemplo para a mudança de percepção refere-se à magnífica compreensão dos agentes econômicos durante a implementação da terceira fase do Plano Real (conversão da URV para o Real). Atualmente, há um grande esforço por parte do governo para guiar as expectativas do público por meio da transparência nas informações (o relatório trimestral do BCB é um bom exemplo) reforçando sua accountability. Portanto, o Brasil reúne as condições necessárias para a adoção de um núcleo de inflação sem traumas: (i) democracia; (ii) incremento na transparência da condução da política econômica; e (iii) comprometimento da autoridade monetária brasileira em assegurar a estabilidade do poder de compra da moeda e a solidez do sistema financeiro nacional.

Um resultado potencial que pode ser extraído da estrutura proposta é que com a maior chance de as metas serem alcançadas há um ganho de credibilidade que permitiria reduções na taxa de juros (aumentaria a chance das expectativas do público estarem próximas do centro da meta). Como conseqüência, os benefícios seriam evidentes, pois implicaria menor pressão para o aumento do endividamento público e, por conseguinte, menor necessidade de superávits primários expressivos. Ademais, com o menor dispêndio em relação ao pagamento dos juros, haveria um aumento dos recursos necessários para implementar a reforma microeconômica que deve ser feita para eliminar os gargalos produtivos do país.

Por último, deve-se ressaltar que, além da visão apresentada neste artigo, de que há uma inadequação do modelo de regras tal como usado pelo BCB, deve-se chamar atenção para um problema oriundo da utilização da regra de Taylor. $\mathrm{O}$ BCB controla a taxa de juros no mercado interbancário, ou seja, uma taxa de curto prazo, enquanto a taxa de juros relevante para afetar as despesas das empresas e famílias é a taxa de longo prazo. Assim, o modelo do BCB deveria incluir uma estimativa a termo da taxa de juros. ${ }^{14}$

\section{REFERÊNCIAS BIBLIOGRÁFICAS}

ARIDA, P. (1999) “Observações sobre o Plano Real”. Economia Aplicada, V. 3, N. especial, 109115.

BANCO CENTRAL DO BRASIL. Relatório de Inflação, diversos números.

BLINDER, A. (2000) “Central-Bank Credibility: Why Do We Care? How Do We Build It?” American Economic Review, 50 (5), December, 1421-1431.

BRESSER-PEREIRA, L.C.; NAKANO, Y. (2002) "Uma Estratégia de Desenvolvimento com Estabilidade”. Revista de Economia Política, 22 (3), julho-setembro, 146-180.

BRYAN, M.F.; CECCHETTI, S.G. (1993) "The Consumer Price Index as a Measure of Inflation." Economic Review, Federal Reserve Bank of Cleveland, 15-24.

${ }^{14}$ Para uma discussão mais precisa deste ponto, ver Tabak e Andrade (2001). 
FIGUEIREDO, F.M.R. (2001) "Evaluating Core inflation Measures for Brazil". Inflation Targeting in Brazil, Brasília, Banco Central do Brasil, 235-254.

FIGUEIREDO, F.M.R.; FERREIRA, T. P. (2002) "Os preços administrados e a inflação no Brasil". Brasília, Banco Centro do Brasil. (Texto para Discussão, n.59)

GONÇALVES, C.E.S. (2001) “Metas de Inflação e Mecanismos de Transmissão de Política Monetária: o caso brasileiro". Economia Aplicada, V. 5, N. 1, janeiro-março, 159-176.

JOHANSEN, S. (1991) "Estimation and Hypothesis Testing of Cointegration Vectors in Gaussian Vector Autoregressive Models," Econometrica, 59, 1551-1580.

MANKIKAR, A.; PAISLEY, J. (2002) "What do measures of core inflation really tell us?" Bank of England Quarterly Bulletin. Winter, V. 42 (4), 373-383.

MENDONÇA, H.F. de (2004) "Dívida Pública e Estabilidade de Preços no Período Pós-Real: explorando relações empíricas”. Estudos Econômicos, FIPE/FEA-USP, Abr- Jun, 34 (2): 345-368. (2003) "Credibilidade das metas de inflação: uma análise aplicada ao caso brasileiro." Revista de Economia Aplicada, FIPE/FEA-USP, outubro-dezembro, V. 7 - N. 4, p. 729-742.

MINELLA, A. (2003) "Monetary Policy and Inflation in Brazil (1975-2000): a VAR Estimation." Revista Brasileira de Economia, 57(3), julho-setembro, 605-635.

PAPADIMITRIOU, D. B.; WRAY, L. R. (1996) “Targeting Inflation: The Effects of Monetary Policy on the CPI and Its Housing Component." Public Policy Brief, N. 27. The Jerome Levy Economics Institute of Board College.

QUAH, D.; VAHEY, S.P. (1995) “Measuring core inflation.” Economic Journal, V. 105 (September), 130-44.

TABAK, B.M.; ANDRADE, S.C. (2001) "Testing the Expectations Hypothesis in the Brazilian Term Structure of Interest Rates.” Texto para discussão do Banco Central do Brasil, N. 30, novembro.

WHITE, H. (1980). “A Heteroskedasticity-Consistent Covariance Matrix and a Direct Test for Heteroskedasticity,” Econometrica, 48, 817-838.

\section{APÊNDICE}

Tabela A.1: Testes de raiz unitária (ADF e PP)

\begin{tabular}{l|cccc|cccc}
\hline & \multicolumn{5}{|c|}{ ADF } & \multicolumn{4}{c}{ PP } \\
\hline Séries & Def. & Teste & $\begin{array}{c}\text { Valor } \\
\text { crítico 1\% }\end{array}$ & $\begin{array}{c}\text { Valor } \\
\text { crítico 5\% }\end{array}$ & Def. & Teste & $\begin{array}{c}\text { Valor } \\
\text { crítico 1\% }\end{array}$ & $\begin{array}{c}\text { Valor } \\
\text { crítico 5\% }\end{array}$ \\
\hline Selic & 1 & $-3,1284$ & $-3,5384$ & $-2,9084$ & 5 & $-0,6228$ & $-2,6016$ & $-1,9460$ \\
\hline D(selic) & 0 & $-2,8749$ & $-2,6022$ & $-1,9461$ & 3 & $-3,1449$ & $-2,6022$ & $-1,9461$ \\
\hline liv & 2 & $-2,4743$ & $-3,5402$ & $-2,9092$ & 5 & $-0,4990$ & $-2,6016$ & $-1,9460$ \\
\hline D(liv) & 1 & $-2,8869$ & $-2,6028$ & $-1,9462$ & 3 & $-4,2869$ & $-2,6022$ & $-1,9461$ \\
\hline adm & 1 & $-1,1856$ & $-2,6022$ & $-1,9461$ & 3 & $-0,9031$ & $-2,6016$ & $-1,9460$ \\
\hline D(adm) & 0 & $-5,4287$ & $-2,6022$ & $-1,9461$ & 0 & $-5,4287$ & $-2,6022$ & $-1,9461$ \\
\hline câmbio & 1 & 0,2893 & $-2,6022$ & $-1,9461$ & 4 & 0,3821 & $-2,6016$ & $-1,9460$ \\
\hline D(câmbio) & 0 & $-5,7791$ & $-2,6022$ & $-1,9461$ & 1 & $-5,7453$ & $-2,6022$ & $-1,9461$ \\
\hline desemp & 4 & $-0,3128$ & $-2,6041$ & $-1,9463$ & 6 & $-0,7278$ & $-2,6016$ & $-1,9460$ \\
\hline
\end{tabular}




\begin{tabular}{l|llll|llll}
\hline D(desemp) & 3 & $-3,9086$ & $-2,6041$ & $-1,9463$ & 37 & $-4,7471$ & $-2,6022$ & $-1,9461$ \\
\hline inf & 1 & $-2,5801$ & $-3,5384$ & $-2,9084$ & 5 & $-0,5255$ & $-2,6016$ & $-1,9460$ \\
\hline D(inf) & 0 & $-3,2856$ & $-2,6022$ & $-1,9461$ & 3 & $-3,3273$ & $-2,6022$ & $-1,9461$ \\
\hline pfi & 0 & 1,6577 & $-2,6016$ & $-1,9460$ & 7 & 1,9507 & $-2,6016$ & $-1,9460$ \\
\hline D(pfi) & 0 & $-7,2924$ & $-2,6022$ & $-1,9461$ & 5 & $-7,2708$ & $-2,6022$ & $-1,9461$ \\
\hline
\end{tabular}

Nota: Teste ampliado de Dickey-Fuller (ADF) — o número de defasagens utilizado para cada série foi definido de acordo com o critério de Schwarz (SC). Para as séries D(selic), D(liv), adm, D(adm), cambio, D (cambio), desemp, $D$ (desemp), inf (para PP), D(inf), pfi e D(pfi) não foi utilizado constante ou tendência. Para as séries Selic, liv e inf (para ADF) foi aplicado constante. Teste Phillip-Perron - Def - defasagem aplicada para Bartlett Kernel. Não foi utilizado constante ou tendência para as séries.

Tabela A.2: Teste de co-integração de Johansen (adm. Liv, selic)

\begin{tabular}{lcccc}
\hline Hipótese nula & Autovalor & Traço & Valor crítico 5\% & Valor crítico 1\% \\
\hline$R=0^{*}$ & 0,349179 & 35,07856 & 29,68 & 35,65 \\
\hline$R £ 1$ & 0,090561 & 7,589226 & 15,41 & 20,04 \\
\hline$R £ 2$ & 0,023377 & 1,513867 & 3,76 & 6,65 \\
\hline
\end{tabular}

Nota: * denota rejeição de $\mathrm{H} 0$ ao nível de significância de $1 \%$.

Tabela A.3: Critério de AIC, SIC e HQ para o VAR

\begin{tabular}{|c|c|c|c|c|c|c|}
\hline \multicolumn{7}{|c|}{ Modelo 1} \\
\hline \multicolumn{4}{|c|}{ com constante } & \multicolumn{3}{|c|}{ sem constante } \\
\hline Def. & AIC & SIC & $\mathrm{HO}$ & AIC & SIC & $\mathrm{HO}$ \\
\hline 0 & 14,56513 & 14,70475 & 14,61975 & & & \\
\hline 1 & 6,281002 & 6,979117 & 6,554073 & 6,679709 & 7,238201 & 6,898166 \\
\hline 2 & $4,997396^{*}$ & $6,254003^{*}$ & $5,488924^{*}$ & $5,197956^{*}$ & $6,314939 *$ & $5,634869^{*}$ \\
\hline 3 & 5,182727 & 6,997825 & 5,892712 & 5,382008 & 7,057484 & 6,037379 \\
\hline 4 & 5,429997 & 7,803587 & 6,358439 & 5,585187 & 7,819154 & 6,459014 \\
\hline 5 & 5,589038 & 8,521120 & 6,735936 & 5,782680 & 8,575140 & 6,874965 \\
\hline \multicolumn{7}{|c|}{ Modelo 2} \\
\hline Def. & AIC & SIC & $\mathrm{HO}$ & $\mathrm{AIC}$ & SIC & $\mathrm{HO}$ \\
\hline 0 & 17,04790 & 17,18752 & 17,10251 & & & \\
\hline 1 & 9,378687 & 10,07680 & 9,651758 & 9,514214 & 10,07271 & 9,732671 \\
\hline 2 & $7,632266^{*}$ & $8,888873^{*}$ & $8,123794^{*}$ & 7,824784 & $8,941768^{*}$ & $8,261698^{*}$ \\
\hline 3 & 7,903683 & 9,718781 & 8,613668 & 7,997843 & 9,673318 & 8,653213 \\
\hline 4 & 7,729246 & 10,10284 & 8,657688 & 7,812317 & 10,04628 & 8,686144 \\
\hline 5 & 7,751221 & 10,68330 & 8,898119 & $7,775020^{*}$ & 10,56748 & 8,867304 \\
\hline
\end{tabular}

Nota: * denota a defasagem selecionada pelo critério. 